\title{
Race, Gender, and Genetic Polymorphism Contribute to Variability in Acetaminophen Pharmacokinetics, Metabolism, and Protein-Adduct Concentrations in Healthy African-American and European-American Volunteers ${ }^{\mathbb{\$}}$
}

\author{
Michael H. Court, Zhaohui Zhu, Gina Masse, Su X. Duan, Laura P. James, \\ Jerold S. Harmatz, and David J. Greenblatt.
}

Pharmacogenomics Laboratory (M.H.C., Z.Z.), Program in Individualized Medicine (PrIMe), Department of Veterinary Clinical Sciences, College of Veterinary Medicine, Washington State University, Pullman, Washington; Program in Pharmacology and Experimental Therapeutics (G.M., S.X.D., J.S.H., and D.J.G.), Tufts University School of Medicine, Boston, Massachusetts; Department of Pediatrics, University of Arkansas for Medical Sciences and Arkansas Children's Hospital Research Institute (L.P.J.), Little Rock, Arkansas

Received May 8, 2017; accepted June 26, 2017

\begin{abstract}
Over 30 years ago, black Africans from Kenya and Ghana were shown to metabolize acetaminophen faster by glucuronidation and slower by oxidation compared with white Scottish Europeans. The objectives of this study were to determine whether similar differences exist between African-Americans and European-Americans, and to identify genetic polymorphisms that could explain these potential differences. Acetaminophen plasma pharmacokinetics and partial urinary metabolite clearances via glucuronidation, sulfation, and oxidation were determined in healthy African-Americans (18 men, 23 women) and European-Americans (34 men, 20 women) following a 1-g oral dose. There were no differences in acetaminophen total plasma, glucuronidation, or sulfation clearance values between AfricanAmericans and European-Americans. However, median oxidation clearance was $37 \%$ lower in African-Americans versus European-Americans $(0.57$ versus $0.90 \mathrm{ml} / \mathrm{min}$ per kilogram; $P=0.0001)$. Although acetaminophen total or metabolite
\end{abstract}

clearance values were not different between genders, shorter plasma half-life values (by $11-14 \% ; P<0.01$ ) were observed for acetaminophen, acetaminophen glucuronide, and acetaminophen sulfate in women versus men. The UGT2B15*2 polymorphism was associated with variant-allele-number proportional reductions in acetaminophen total clearance (by $15-27 \% ; P<0.001$ ) and glucuronidation partial clearance (by 23-48\%; $P<0.001$ ). UGT2B15 ${ }^{*} 2 /{ }^{*} 2$ genotype subjects also showed higher acetaminophen protein-adduct concentrations than ${ }^{*} 1 /{ }^{*} 2$ (by $42 \% ; P=$ 0.003 ) and ${ }^{*} 1{ }^{*} 1$ (by $41 \% ; P=0.003$ ) individuals. Finally, CYP2E1 ${ }^{*} 1 \mathrm{D} /{ }^{*} 1 \mathrm{D}$ genotype African-Americans had lower oxidation clearance than ${ }^{*} 1 \mathrm{C} /{ }^{*} 1 \mathrm{D}$ (by $42 \% ; P=0.041$ ) and ${ }^{*} 1 \mathrm{C} /{ }^{*} 1 \mathrm{C}$ (by $44 \% ; P=$ $0.048)$ African-Americans. Consequently, African-Americans oxidize acetaminophen more slowly than European-Americans, which may be partially explained by the CYP2E1*1D polymorphism. UGT2B15*2 influences acetaminophen pharmacokinetics in both African-Americans and European-Americans.

\section{Introduction}

Acetaminophen is one of the most commonly used nonprescription drugs for treating mild pain and fever in the United States of America (Ameer and Greenblatt, 1977; Kaufman et al., 2002). This drug is also the most common cause in the United States of acute liver failure resulting from intentional or inadvertent drug overdose (Larson et al., 2005). Recent studies in our laboratory using patient DNA samples

This work was supported by the National Institutes of Health National Institute of General Medical Sciences [Grants R01-GM061834 and R01GM102130] to M.H.C.

https://doi.org/10.1124/jpet.117.242107.

S This article has supplemental material available at jpet.aspetjournals.org. collected by the Acute Liver Failure Study Group have identified polymorphisms associated with acetaminophen-induced acute liver failure in genes encoding enzymes that metabolize acetaminophen, including UDP-glucuronosyltransferase (UGT) 1A and cytochrome P450 3A5 (CYP3A5) (Court et al., 2013; Court et al., 2014). Interestingly, acetaminophen-induced liver failure patients identified by the Acute Liver Failure Study Group were primarily female (74\%) and white (88\%), with only $5 \%$ of subjects identified as African-American (Larson et al., $2005)$. This differs from the reported race distribution $(\sim 60 \%$ white and $\sim 12 \%$ African-American) and gender distribution ( $\sim 51 \%$ women) for the U.S. population over the same study period (census.gov). Although there are probable alternate explanations for this observation, it is possible that these

ABBREVIATIONS: ABT-751, N-(2-((4-Hydroxyphenyl)amino)-3-pyridinyl)-4-methoxybenzenesulfonamide; ALT, alanine aminotransferase; ANOVA, analysis of variance; APAP, acetaminophen; AUC, total area under the plasma concentration curve; HPLC, high-performance liquid chromatography; NAPQI, $N$-acetyl-p-benzoquinone imine; PCR, polymerase chain reaction; SNP, single-nucleotide polymorphism; UGT, UDP-glucuronosyltransferase; SULT, sulfotransferase. 
demographic differences reflect variable susceptibility to toxicity because of race and gender differences in acetaminophen metabolism. Unfortunately, relatively few studies have characterized such metabolic differences.

Over 30 years ago, it was shown that blacks from Ghana and Kenya excreted similar amounts (on the basis of 24-hour fractional urinary recovery) of acetaminophen (APAP) sulfate, higher amounts of APAP glucuronide, and lower amounts of APAP glutathione conjugates (derived from NAPQI) compared with whites from Scotland (Critchley et al., 1986). This finding was suggested as an explanation of the lower incidence of APAP hepatotoxicity in Africans compared with whites (Critchley et al., 2005). Race-associated differences in acetaminophen metabolism may be a consequence of differences in the population frequencies of genetic polymorphisms. As far as we are aware, studies of APAP pharmacokinetics or metabolism have not been reported for African-Americans.

There is some evidence for gender-associated differences in APAP pharmacokinetics and metabolism. After controlling for body-size differences, about $20 \%$ higher acetaminophen oral clearance was also observed in young men versus young women but not in elderly men versus women (Divoll et al., 1982). However, another study showed no differences in weight-adjusted acetaminophen clearance after intravenous acetaminophen administration but did show higher weightadjusted acetaminophen volume of distribution values in men versus women (Abernethy et al., 1982). Higher APAP glucuronide fractional excretion and lower APAP sulfate excretion was observed in men compared with women in both Scottish white and Ghanaian populations but not in the Kenyan population (Critchley et al., 1986). Using human liver microsomes, we also showed approximately 50\% higher APAP glucuronidation in livers from male donors compared with female donors (Court et al., 2001).

Several studies have evaluated associations of acetaminophen pharmacokinetics with drug-metabolizing-enzyme genotypes. Urinary acetaminophen glucuronide metabolite concentrations were not associated with Gilbert's syndrome (caused by the UGT1A1*28 promoter variant) in a study of 23 healthy white European volunteers (Rauchschwalbe et al., 2004). Slightly higher acetaminophen clearance was associated with a UGT1A $6 * 2 /$ UGT1A1*28 haplotype in a study of 15 Thai $\beta$-thalassemia patients (Tankanitlert et al., 2007). The UGT2B15*2 (rs1902023) polymorphism was associated with decreased acetaminophen glucuronide concentrations in urine samples from 66 healthy white and Asian volunteers in the United States (Navarro et al., 2011). This finding was confirmed by a study of 109 Pakistani volunteers that showed lower blood acetaminophen glucuronide-to-acetaminophen concentration ratios with an increasing number of UGT2B15*2 alleles (Mehboob et al., 2016). However, studies evaluating genetic associations with acetaminophen sulfation or oxidation have not been reported.

Although at therapeutic doses acetaminophen-derived NAPQI largely undergoes conjugation with glutathione, it can also covalently bind with liver proteins. A high-performance liquid chromatography (HPLC) with electrochemical detection assay has been developed that can quantitatively measure acetaminophen protein-adduct concentrations in patient blood samples following therapeutic and toxic acetaminophen concentrations (Davern et al., 2006; Heard et al., 2011; James et al., 2013). This assay has been used to identify cases of acetaminophen-induced acute liver failure in which the precipitating cause was initially indeterminate (James et al., 2006; Khandelwal et al., 2011). Currently, it is unclear whether race, gender, or genetics influences acetaminophen protein-adduct concentrations.

The main objective of this study was to determine whether acetaminophen pharmacokinetics, metabolism, and proteinadduct formation differ between African-American and European-American men and women. We also evaluated whether selected polymorphisms in candidate genes for enzymes involved in acetaminophen glucuronidation, sulfation, and oxidation were associated with differences in acetaminophen metabolic clearance and protein-adduct formation.

\section{Materials and Methods}

Subjects. The study protocol and consent form were reviewed and approved by the Institutional Review Boards serving Tufts University School of Medicine (Boston, MA) and Promedica Clinical Research Center (Boston, MA). The ClinicalTrials.gov identifier for this study was NCT00768716. Healthy self-declared European-American (or white or Caucasian) and African-American (or black) men and women aged 18-64 years were recruited from the local population. The planned enrollment was 100 with an approximately equal distribution of subjects by gender and race. Exclusion criteria included a history of medical disease, any clinically significant abnormality detected by physical examination or routine laboratory analysis, HIV or hepatitis (B or C) infection, a history of tobacco use or consuming an average of three or more alcohol drinks per day, pregnancy, or the use of drugs or herbal medications known to alter acetaminophen metabolism. Specific medications included isoniazid, disulfiram, phenobarbital, phenytoin, carbamazepine, rifampicin, valproic acid, probenecid, and St. John's Wort. Additionally, all subjects were asked to refrain from consuming any type of caffeinated products or grapefruit juice on the study day.

Study Procedures. On the day of the study, subjects reported to the study unit at $7 \mathrm{AM}$, received a light breakfast, and had a catheter placed into a forearm vein for serial collection of blood samples. Baseline plasma, serum, and urine samples were collected and subsequently stored at $-80^{\circ} \mathrm{C}$. Two $500-\mathrm{mg}$ acetaminophen tablets (Extra Strength Tylenol; McNeil, Fort Washington, PA) were then administered at $8 \mathrm{AM}$ under direct observation with a glass of water. No food or drink (except water) was permitted until 2 hours after acetaminophen administration. Plasma samples were collected at 1, 2, $3,4,5,6,8,10$, and 12 hours after acetaminophen dosing and stored at $-80^{\circ} \mathrm{C}$ with the baseline sample. All voided urine was collected throughout the study into a refrigerated container up until 12 hours after acetaminophen administration. The final urine volume collected was then measured, an aliquot was stored at $-80^{\circ} \mathrm{C}$, and the subject was discharged. Subjects returned 4 days after acetaminophen administration (on day 5) for collection of a second serum sample. Serum samples were assayed for alanine aminotransferase levels within 24 hours of collection by a commercial laboratory (Quest Diagnostics, Madison, $\mathrm{NJ}$ ). Plasma and urine samples stored at $-80^{\circ} \mathrm{C}$ were assayed for acetaminophen and metabolite concentrations within 12 months of collection.

Acetaminophen and Metabolite Concentration Assays. Plasma samples were assayed for acetaminophen, acetaminophen glucuronide, and acetaminophen sulfate concentrations by HPLC with UV absorbance detection using the same method we have recently reported in detail (Zhao et al., 2015). Calibration curves were consistently linear $\left(\mathrm{R}^{2}>0.99\right)$ over the assayed range with the limit of quantitation was $0.1 \mu \mathrm{g} / \mathrm{ml}$ for each analyte. Quality control samples with low and high analyte concentrations showed excellent precision $(<15 \%$ coefficient of variation) and accuracy $(89-104 \%$ of 
nominal). Concentrations in unknown plasma samples were determined in duplicate on two separate occasions and the results were averaged.

Acetaminophen, acetaminophen glucuronide, acetaminophen sulfate, acetaminophen mercapturate, and acetaminophen cysteinate concentrations were determined in urine samples by HPLC with mass spectrometry detection. Pure standards and the respective stable isotope-labeled internal standards were purchased from Toronto Research Chemicals (Toronto, Ontario, Canada). Briefly, $5 \mu \mathrm{l}$ of urine was diluted to $500 \mu \mathrm{l}$ volume with $0.5 \%$ (v/v) formic acid in water. After adding internal standards, including acetaminophen-D4 (20 ng), acetaminophen-D3 glucuronide (500 ng), acetaminophen-D3 sulfate (200 ng), and acetaminophen mercapturate-D5 (200 ng), the sample was mixed, and $20 \mu \mathrm{l}$ was analyzed by HPLC (Agilent 1100; Agilent Technologies, Santa Clara, CA) with a triple quadrupole mass spectrometry detector (AB-Sciex API4000, Applied Biosystems Life Technologies; Thermo Fisher Scientific, Framingham, MA). The mobile phase consisted of $0.5 \% \mathrm{v} / \mathrm{v}$ formic acid in water (A) mixed with acetonitrile (B) that was pumped at $400 \mu \mathrm{l}$ per minute through a 2.0-mm $\times 150-\mathrm{mm} 4-\mu \mathrm{m}$ C18 column (Synergi Fusion RP; Phenomenex, Torrance, CA). Separation of analytes was achieved through use of a mobile phase gradient starting at an $\mathrm{A} / \mathrm{B}$ ratio of $75: 25$ until 0.5 minutes, linearly changing to 5:95 at 1.5 minutes, and returning to 75:25 at 1.6 minutes with a total run time of 5 minutes. Positive ion mass transitions monitored included $\mathrm{m} / z 152 \rightarrow 110$ (acetaminophen), $\mathrm{m} / z \quad 156 \rightarrow 114$ (acetaminophen-D4), $\mathrm{m} / z$ 328 $\rightarrow 152$ (acetaminophen glucuronide), $\mathrm{m} / z \quad 331 \rightarrow 155$ (acetaminophen-D3 glucuronide), $\mathrm{m} / z$ $232 \rightarrow 152$ (acetaminophen sulfate), $m / z 235 \rightarrow 155$ (acetaminophen-D3 sulfate), $m / z 335 \rightarrow 152$ (acetaminophen mercapturate), $m / z 340 \rightarrow 152$ (acetaminophen mercapturate-D5), and $\mathrm{m} / z$ 271 $\rightarrow 140$ (acetaminophen cysteinate). Retention times for acetaminophen cysteinate, acetaminophen glucuronide, acetaminophen mercapturate, acetaminophen, and acetaminophen sulfate (and the applicable corresponding labeled isotopes) were 1.0, 1.1, 1.5, 1.6, and 1.7 minutes (respectively). Acetaminophen mercapturate-D5 was used as the internal standard for acetaminophen cysteinate since an isotope-labeled derivative was not commercially available.

Calibration curves were generated using drug-free urine spiked with known concentrations of acetaminophen $(0.5-50 \mu \mathrm{g} / \mathrm{ml})$, acetaminophen glucuronide $(25-2500 \mu \mathrm{g} / \mathrm{ml})$, acetaminophen sulfate (5-500 $\mu \mathrm{g} / \mathrm{ml})$, acetaminophen mercapturate $(2.5-250 \mu \mathrm{g} / \mathrm{ml})$, and acetaminophen cysteinate $(2.5-250 \mu \mathrm{g} / \mathrm{ml})$. Curves were linear $\left(\mathrm{R}^{2}>\right.$ $0.99)$ over the assayed range. The assay showed excellent precision $(<15 \%$ coefficient of variation) and accuracy $(<10 \%$ deviation from nominal) over the concentrations assayed. Analyte concentrations in unknown urine samples were determined in duplicate on two separate occasions and the results were averaged.

Acetaminophen Protein-Adduct Assay. Baseline and 8-hour postadministration samples were analyzed within 6 months of collection by HPLC with electrochemical detection as described previously (Davern et al., 2006; Khandelwal et al., 2011). Briefly, samples were gel-filtered and hydrolyzed to release acetaminophen-cysteine from acetaminophen protein-adducts. Following protein precipitation and extraction, samples were injected on the HPLC system, resolved on a $150-\mathrm{mm}$ C18 column (Symmetry, Waters, Milford, MA) using a mobile phase containing $8 \% \mathrm{v} / \mathrm{v}$ methanol and $50 \mathrm{mM}$ sodium acetate in water ( $\mathrm{pH} 4.8$ ), and detected using a coulometric electrochemical detector (Esa Biosciences, Chelmsford, MA). Final acetaminophen protein-adduct concentrations were reported as nmol APAP-cys $/ \mathrm{ml}$ plasma.

Pharmacokinetic Calculations. A plot of log-transformed plasma concentration versus time was constructed for each analyte for each subject. The terminal log-linear phase of the plasma concentration curve was identified visually. The beginning and ending time points were designated as the regression interval. The slope (beta) of the terminal phase over the designated regression interval was calculated by log-linear regression and used to calculate the elimination half-life $\left(t_{1 / 2}=(\ln 2) /\right.$ beta $)$. The total area under the plasma concentration curve (AUC) was calculated using the linear trapezoidal method from time zero to 12 hours, and extrapolated to infinity by addition of the terminal segment calculated by dividing the final measured concentration by beta. The weight-normalized apparent oral clearance of acetaminophen was calculated by dividing the acetaminophen dose by the acetaminophen total AUC and by the subject's body weight. The molar fraction of unchanged acetaminophen, acetaminophen glucuronide, acetaminophen sulfate, and oxidative acetaminophen metabolites (summed mercapturate and unbound cysteinate) in the zero- to 12-hour urine samples from each subject was used to calculate the partial urinary clearance of acetaminophen and each metabolite from the apparent oral plasma clearance of acetaminophen. These latter calculations assume that renal excretion is the predominant mechanism for elimination of acetaminophen metabolites and that the majority of acetaminophen metabolites are excreted in the urine within 12 hours of administration. This latter assumption is supported by prior work that showed $84 \%$ of the radioactivity of a dose of radiolabeled acetaminophen was recovered in the urine within 12 hours and 90\% within 24 hours (Mitchell et al., 1974).

Genotyping. DNA was extracted using a spin column kit (QIAamp DNA Blood Mini Kit; Qiagen, Germantown, MD) from the buffy coat fraction of blood samples collected from each subject. DNA samples were then genotyped using a real-time polymerase chain reaction (PCR) instrument (CFX96 Touch; Bio-Rad, Hercules, CA) by allele discrimination assays (Applied Biosystems TaqMan SNP Genotyping Assay; Thermo Fisher Scientific, Waltham, MA). Variants assayed included the UGT1A $6 * 2$ haplotype single-nucleotide polymorphisms (SNPs) consisting of rs6759892 (S7A; C__1432204), rs2070959 (T181A; C__15868110), and rs1105879 (R184S; C_1173642), as well as UGT1A9 rs6714486 (-275T>A; C_27843087), UGT1A3'UTR rs8330 (c.2042C>G; C__7607429), UGT2B15*2 rs1902023 (D85Y; C__27028164), CYP3A5*3 rs776746 (C_26201809), and CYP2E1*4 rs6413419 (V179I; C__30443971). The UGT1A1 -53(TA) $\times$ $5,6,7$, or 8 variable-length dinucleotide insertion/deletion polymorphisms were genotyped by Genescan fragment-length analysis as previously reported (Girard et al., 2005). The CYP2E1*1D tandem repeat polymorphism $(6$ repeats in the $* 1 \mathrm{C}$ allele and 8 repeats in the *1D allele) was assayed by PCR with agarose gel sizing (Court et al., 2014), whereas the SULT1A1*2 polymorphism (rs9282861, R213H) was assayed by a PCR-restriction fragment length polymorphism (RFLP) method (Court et al., 2014). Assay accuracy was confirmed through direct sequencing of PCR product from representative samples. All observed genotype frequencies were determined to be consistent with expected genotype frequencies according to the Hardy-Weinberg distribution $\left(P>0.05 ; \chi^{2}\right.$ test $)$.

Statistical Analyses. Statistical analyses were performed using Sigmaplot 12 software (Systat, San Jose, CA). All data were summarized as median and range (demographic data) or as median and interquartile range (pharmacokinetic data) values. Comparisons between groups were performed using parametric tests, unless the Shapiro-Wilk test indicated non-normality or the Brown-Forsythe test indicated unequal variance, in which case an equivalent nonparametric test was used (indicated below). A $P$ value of less than 0.05 was considered significant. Demographic characteristics were compared between racial and gender groups by either Mann-Whitney rank sum test (continuous data) or by $\chi^{2}$ test (frequency data). Spearman rank order correlation was used to evaluate associations between acetaminophen total plasma clearance, partial clearance, and protein-adduct concentrations. Pharmacokinetic parameters were log-transformed prior to statistical comparisons between demographic and enzyme genotype groups. These groups were compared by either $t$ test (two groups) or ANOVA (three groups). In instances when ANOVA indicated a significant difference between groups, multiple pairwise comparisons (Holm-Sidak method) were performed to identify the groups that were different from each other. The distribution of plasma acetaminophen protein-adduct concentration data remained non-normal (Shapiro-Wilk test $P<0.05$ ) despite logtransformation. Consequently these data were analyzed by non-parametric 
methods, including either Mann-Whitney rank sum test (2 groups) or Kruskal-Wallis ANOVA on ranks (three groups) with post-hoc testing (when appropriate) by Dunn's multiple comparisons procedure. Multiple linear regression was used to evaluate the possible contributions of race, gender, BMI, and enzyme genotypes to variability in acetaminophen and metabolite clearance, as well as acetaminophen protein-adduct formation.

\section{Results}

The demographic characteristics of the study participants are summarized in Table 1 . Of 104 subjects who met enrollment criteria and entered the study, 98 subjects (55 European-Americans and 43 African-Americans) completed the study. The primary reason for failure to complete the study was an inability to obtain satisfactory venous access for serial blood samples. Data from three subjects (one European-American man and two African-American women) were excluded since predose plasma samples contained significant concentrations of acetaminophen. Urine samples from two African-Americans (one man and one woman) and the DNA sample from one European-American man were lost to analysis, and so acetaminophen partial clearances and genotypes (respectively) could not be determined for those subjects. As shown in Table 1, there was a similar distribution of age, weight, drinking history, and female hormonal contraceptive use between EuropeanAmericans and African-Americans. However, there was a higher proportion of women (56\% versus $37 \%$ ) and a higher median body mass index ( 26 versus $24 \mathrm{~kg} / \mathrm{m}^{2}$ ) in the AfricanAmerican group compared with the European-American group (respectively). Table 1 also gives baseline serum alanine aminotransferase (ALT) values and the change in serum ALT values at 4 days after acetaminophen administration. Baseline ALT values did not differ between racial groups, and there was no change in ALT values for either racial group after acetaminophen administration $(P>$ 0.05).

A plot showing mean ( \pm standard error) plasma concentrations of acetaminophen and its glucuronide and sulfate metabolites for all subjects measured up to 12 hours after dosing is shown in Fig. 1. Median (interquartile range) acetaminophen plasma clearance, glucuronidation clearance, sulfation clearance, oxidation clearance, and unchanged acetaminophen renal clearance values for all subjects were 5.5 (4.8-6.6), 3.0 (2.3-4.0), 1.5 (1.1-1.9), 0.76 (0.57-1.0), and 0.17 (0.14-0.23) $\mathrm{ml} / \mathrm{min}$ per kilogram. Spearman correlation analysis (Fig. 2) showed the strongest correlation of acetaminophen plasma clearance with acetaminophen glucuronidation clearance $(\mathrm{Rs}=0.90, P<0.001)$ and sulfation clearance $(\mathrm{Rs}=0.50$,
$P<0.001$ ), with much weaker correlations with acetaminophen oxidation ( $\mathrm{Rs}=0.23, P=0.03)$, and unchanged renal clearance $(\mathrm{Rs}=0.21, P=0.04)$. Median (interquartile range) plasma acetaminophen protein-adduct concentrations were 0.021 (0.014-0.027) nmoles/ml for all subjects. Acetaminophen protein-adduct concentrations were most strongly and negatively correlated with acetaminophen glucuronidation clearance $(\mathrm{Rs}=-0.60, P<0.001)$ followed by acetaminophen plasma clearance $(\mathrm{Rs}=-0.46 P<0.001)$ (Fig. 3) but were not correlated with acetaminophen sulfation $(\mathrm{Rs}=-0.07, P=0.5)$, oxidation ( $\mathrm{Rs}=0.18, P=0.10)$ or unchanged renal clearance $(\mathrm{Rs}=-0.04, P=0.7)$ (data not shown).

Pharmacokinetic parameters for European-American and African-American subjects are compared in Table 2. No differences were observed between these groups except for acetaminophen oxidation partial clearance, which showed a $37 \%$ lower median value $(P=0.0001)$ in African-Americans compared with European-Americans. Pharmacokinetic parameters were also compared between genders (Table 3). Shorter median half-life values were observed for acetaminophen (by $11 \% ; P=0.0009$ ), acetaminophen glucuronide (by $14 \% ; P=0.0002$ ), and acetaminophen sulfate (by $11 \% ; P=$ 0.002 ) in women compared with men. Lower median plasma metabolite/acetaminophen AUC ratios were also observed for acetaminophen glucuronide (by $17 \% ; P=0.049$ ) and acetaminophen sulfate (by $14 \% ; P=0.025$ ) in women compared with men.

The minor allele frequencies for the enzyme variants assayed in the study subjects (given in Table 4) were in general agreement with reported dbSNP values (https://www.ncbi.nlm.nih.gov/ projects/SNP/) for the corresponding racial group. Higher minor allele frequencies $\left(P<0.05, \chi^{2}\right.$ test) were observed for UGT1A rs8330, UGT1A9 rs6714486, CYP2E1*1D, and CYP2E1*4 in African-American compared with European-American subjects, whereas lower frequencies were found for UGT1A $6 * 2$ and CYP3A5*3. On the other hand, UGT1A1 (TA)n, UGT2B15*2, and SULT1A1*2 allele frequencies did not differ between racial groups.

Associations were then evaluated between acetaminophen pharmacokinetic parameters and enzyme genotypes. These genetic variants were chosen on the basis of prior evidence for functional impact on the enzymes known to be involved in acetaminophen metabolism (Court et al., 2014). In instances where the number of individuals with the homozygous variant genotype were small ( $<5$ individuals), data were also analyzed by combining the heterozygous and homozygous variant groups (variant carrier) to increase statistical power. As shown in Fig. 4A, acetaminophen plasma clearance varied by UGT2B15*2 genotype in direct proportion to the number of variant T alleles (ANOVA, $P<0.001$; Supplemental Table 1).

TABLE 1

Demographic characteristics of study subjects

\begin{tabular}{lccc}
\hline \multicolumn{1}{c}{ Parameter } & European-Americans $(N=54)$ & African-Americans $(N=41) P$ value $^{a}$ \\
\hline Age, years [median (range)] & $30(18-60)$ & $43(19-61)$ & 0.07 \\
Men/women $[N(\%)]$ & $34 / 20(63 / 37 \%)$ & $18 / 23(44 / 56 \%)$ & 0.01 \\
Weight, kg [median (range)] & $72(52-100)$ & $73(55-112)$ & 0.19 \\
Body mass index, kg/m ${ }^{2}$ [median (range)] & $24(17-30)$ & $26(20-36)$ & 0.01 \\
Nondrinkers $[N(\%)]$ & $14(26 \%)$ & $8(20 \%)$ & 0.34 \\
Hormonal contraceptive use [N (\% of women)] & $5(25 \%)$ & $3(13 \%)$ & 0.19 \\
Serum ALT at baseline, IU/l [median (range)] & $18(9-63)$ & $15(7-43)$ & 0.17 \\
Change in ALT at 4 days, U/l [median (range)] & $0(-41$ to +9) & $0(-10$ to +10$)$ & 0.90 \\
\hline
\end{tabular}

${ }^{a}$ Mann-Whitney rank sum test or $\chi^{2}$ test for gender, drinking history, and hormonal contraceptive use. 


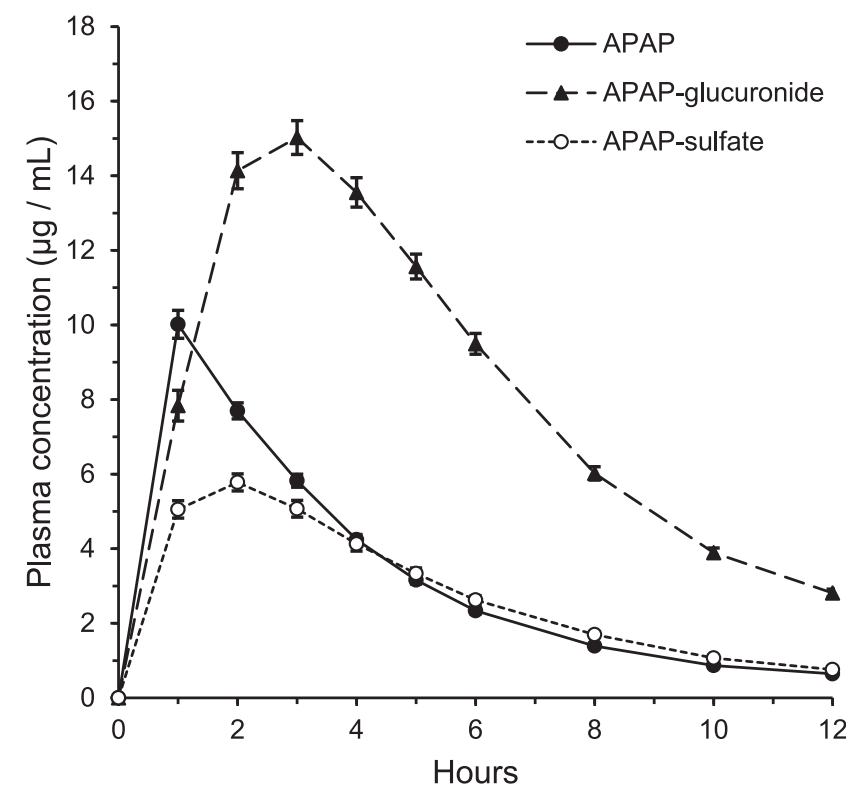

Fig. 1. Mean ( \pm standard error) plasma concentrations of acetaminophen (APAP) and its glucuronide and sulfate metabolites (APAP-glucuronide, APAP-sulfate) at corresponding times across all subjects administered $1 \mathrm{~g}$ of acetaminophen by mouth.

UGT2B15 *2/*2 individuals showed $27 \%$ lower median acetaminophen clearance than $* 1 / * 1$ individuals $(P<0.001)$ and $15 \%$ lower than $* 1 / * 2$ individuals $(P=0.021)$, whereas $* 1 / * 2$ individuals were $14 \%$ lower than $* 1 / * 1$ individuals $(P=0.03)$. However, none of the other enzyme genotypes evaluated were associated with acetaminophen plasma clearance (Supplemental Table 1). A similar but stronger association [analysis of variance (ANOVA), $P<0.001$; Supplemental Table 2] was observed between UGT2B15*2 genotype and glucuronidation partial clearance (Fig. 4B). UGT2B15 *2/*2 genotype individuals showed $48 \%$ lower median glucuronidation clearance than $* 1 / * 1$ individuals $(P<0.001)$ and $32 \%$ lower than $* 1 / * 2$ individuals $(P<0.001)$, whereas $* 1 / * 2$ individuals were $23 \%$ lower than $* 1 / * 1$ individuals $(P=0.03)$. None of the other glucuronidation enzyme polymorphisms evaluated were associated with variation in glucuronidation partial clearance (Supplemental Table 2). A similar trend was also observed for plasma glucuronide/ acetaminophen AUC ratios with lower median ratios associating with an increasing number of variant UGT2B15*2 alleles (ANOVA, $P<0.001$; Supplemental Table 2). Again, none of the other glucuronidation enzyme polymorphisms correlated with glucuronide/acetaminophen AUC ratios (Supplemental Table 2).

As shown in Supplemental Table 3, although no association (ANOVA, $P=0.41$ ) was observed between the SULT1A1*2 variant and sulfation partial clearance, there was a weak association (ANOVA, $P=0.04$ ) between this variant and plasma sulfate/ acetaminophen ratios. SULT1A1 $* 2 / 2$ genotype individuals showed $30 \%$ lower $(P=0.04)$ and $22 \%$ lower $(P=0.043)$ median AUC ratios than $\mathrm{A} / \mathrm{G}$ and $* 1 / * 1$ individuals (respectively), whereas $\mathrm{A} / \mathrm{G}$ and $* 1 * 1$ individuals were not different $(P=0.75)$.
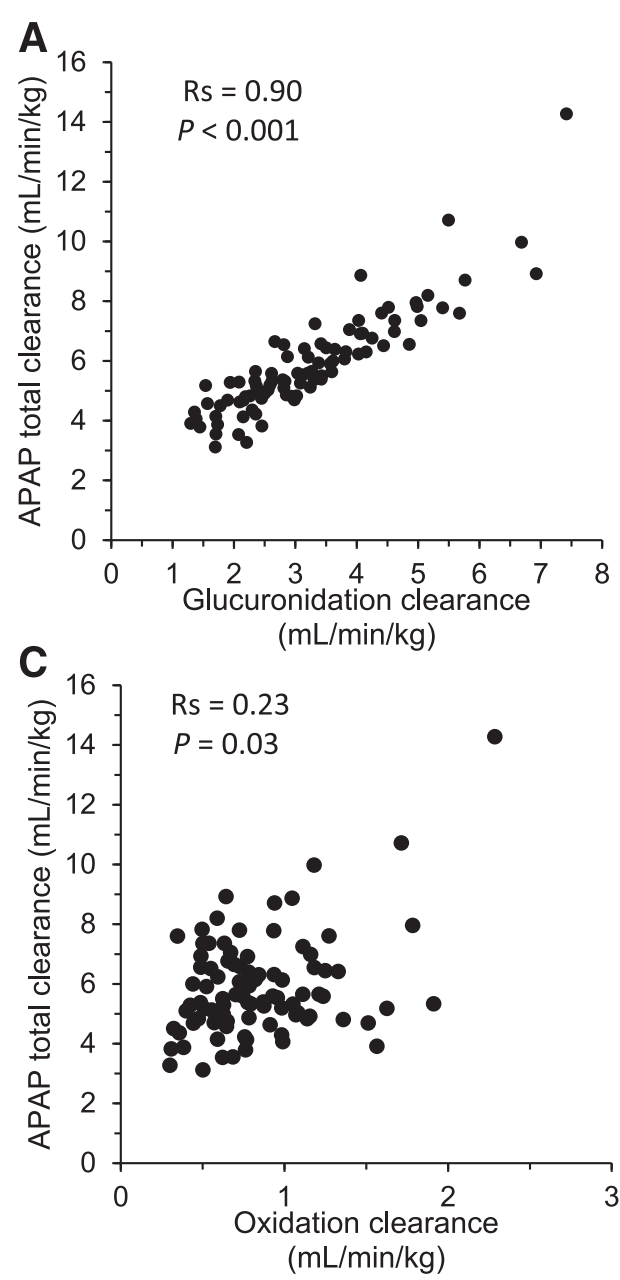
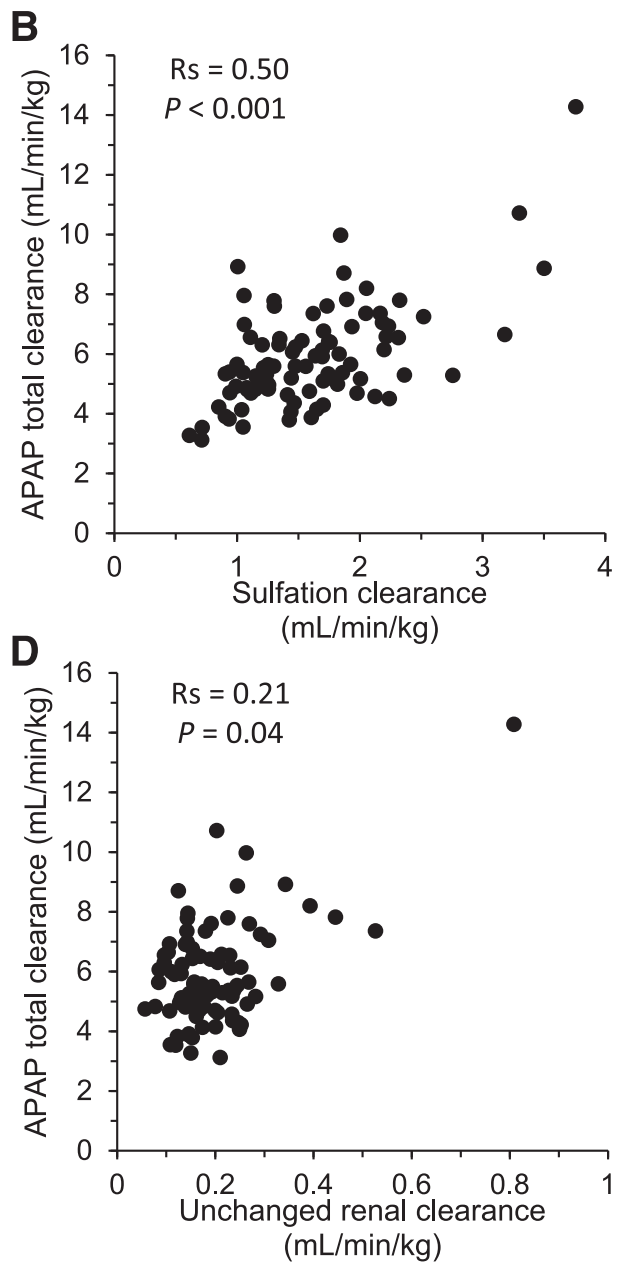

Fig. 2. Correlation of APAP total plasma clearance with partial urinary clearance by glucuronidation (A), sulfation (B), oxidation (C), and unchanged renal excretion (D) measured in 95 subjects (54 EuropeanAmericans and 41 African-Americans; 52 men and 43 women) administered $1 \mathrm{~g}$ of acetaminophen by mouth. Acetaminophen oxidation clearances are calculated from the sum of the glutathione-derived cysteinate and mercapturate metabolites. Also shown are the Spearman correlation coefficients (Rs) and associated $P$ values. 

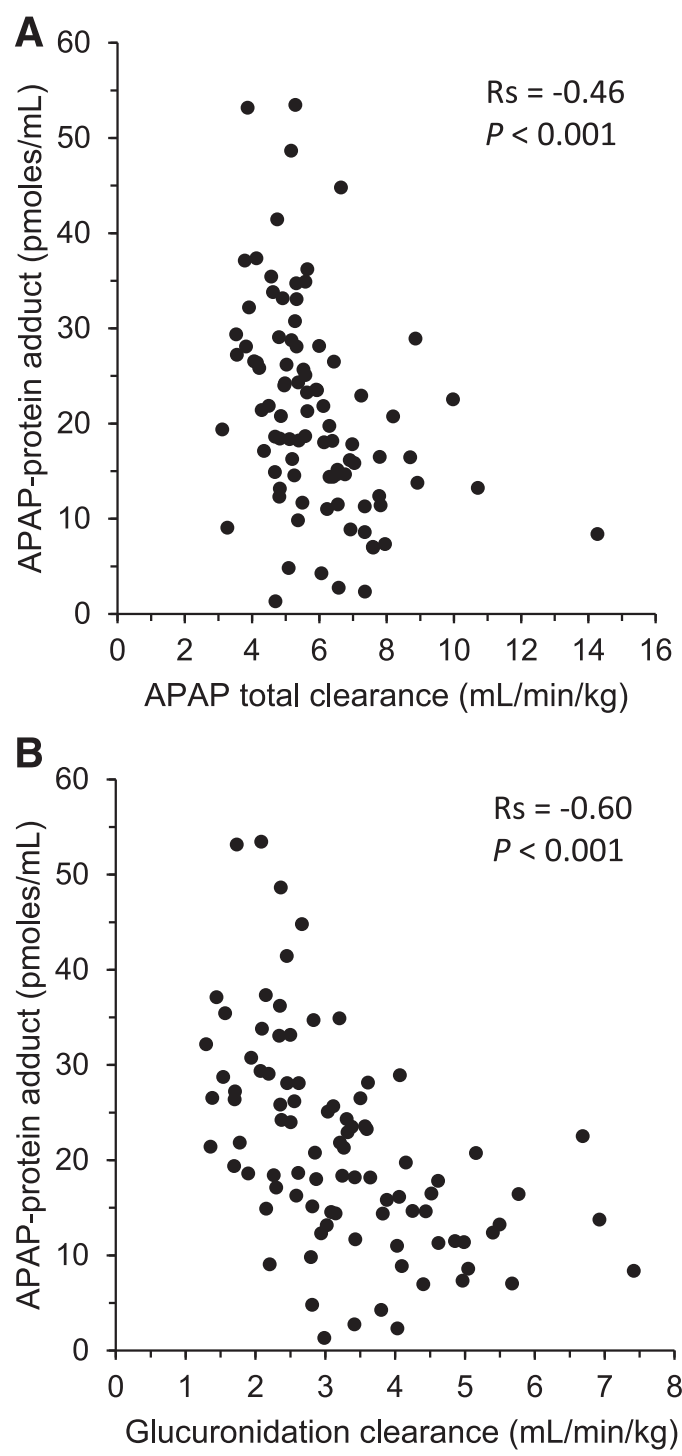

Fig. 3. Correlation of total acetaminophen plasma clearance (A) and partial glucuronidation clearance (B) with plasma acetaminophen proteinadduct concentrations measured in 95 subjects (54 European-Americans and 41 African-Americans; 52 men and 43 women) at 8 hours after administration of $1 \mathrm{~g}$ of acetaminophen by mouth. Also shown are the Spearman correlation coefficients (Rs) and associated $P$ values.

Initial analysis of the association of acetaminophen oxidation partial clearance with oxidation enzyme genotypes in all subjects showed significant correlations with all genotypes evaluated (Supplemental Table 4). However, since both oxidation partial clearance (Table 2) and the frequencies of these polymorphisms (Table 4) varied by race, this result could simply be a consequence of stratification of subjects by raceassociated genetic variants. Subsequent analysis within each racial group showed a weak association (ANOVA, $P=0.048$ ) of the CYP2E1*1D variant with oxidation clearance in AfricanAmerican subjects (Fig. 5 and Supplemental Table 5). Individuals with the CYP2E1 $* 1 \mathrm{D} / * 1 \mathrm{D}$ genotype showed $42 \%$ lower $(P=0.041)$ and $44 \%$ lower $(P=0.048)$ median oxidation clearance than $* 1 \mathrm{C} / * 1 \mathrm{D}$ and $* 1 \mathrm{C} / * 1 \mathrm{C}$ individuals (respectively), whereas $* 1 \mathrm{C} / * 1 \mathrm{D}$ and $* 1 \mathrm{D} / * 1 \mathrm{D}$ individuals were not different $(P=0.74)$. No significant associations were found for other genotypes in African-American subjects, or for any genotype in European-American subjects (Supplemental Table 5). However, it should be noted that the frequencies of these polymorphisms were much lower in European-American subjects and none of them were homozygous for the variant allele of any of the oxidative enzyme polymorphisms tested.

Finally, we evaluated enzyme genotype associations with plasma acetaminophen-adduct concentrations measured at 8 hours after drug administration in all subjects (Supplemental Table 6). This corresponded to the time at which the acetaminophen-adduct plasma concentration was predicted to be highest (i.e., the $\mathrm{T}_{\max }$ ) on the basis of the results of a previous study (James et al., 2013). As shown in Fig. 6, only UGT2B15*2 genotype was significantly correlated with acetaminophen protein-adduct concentration (ANOVA, $P=0.003$ ), with $* 2 / * 2$ genotype individuals showing $41 \%$ higher concentrations than $* 1 / * 1$ individuals $(P=0.003)$ and $42 \%$ higher than $* 1 / * 2$ individuals $(P=0.014)$, whereas $* 1 / * 2$ individuals were not different from $* 1 / * 1$ individuals $(P=1.0)$.

Given that multiple factors could contribute to pharmacokinetic variability, we conducted a multivariate analysis by linear regression incorporating independent variables shown to be associated with pharmacokinetic parameters in the preceding univariate analyses, including race, gender, as well as UGT2B15*2, SULT1A2*2, and CYP2E1*1D genotypes. As shown in Table 5, UGT2B15*2 genotype was the only variable that was predictive of acetaminophen plasma clearance, glucuronidation clearance, and acetaminophen proteinadduct concentrations, accounting for $17 \%, 29 \%$, and $19 \%$ (respectively) of the observed variability. Both gender and UGT2B15*2 genotype were predictive of glucuronide-toacetaminophen AUC ratios (30\% of the observed variability), and both race and CYP2E $1 * 1 \mathrm{D}$ genotype were predictive of acetaminophen oxidative clearance $(23 \%$ of the observed

TABLE 2

Comparisons of APAP pharmacokinetic parameters in study subjects by race

Data presented as median (interquartile range).

\begin{tabular}{lccc}
\hline \multicolumn{1}{c}{ Parameter } & European-Americans $(N=54)$ & African-Americans $(N=41) P$ value $^{a}$ \\
\hline APAP t $_{1 / 2}(\mathrm{~h})$ & $2.5(2.4-2.8)$ & $2.5(2.4-3.1)$ & 0.24 \\
APAP plasma clearance (ml/min per kilogram) & $5.3(4.8-6.4)$ & $5.9(5.1-6.9)$ & 0.52 \\
APAP renal clearance $(\mathrm{ml} / \mathrm{min}$ per kilogram) & $0.16(0.14-0.20)$ & $0.20(0.15-0.24)$ & 0.31 \\
APAP glucuronide $\mathrm{t}_{1 / 2}(\mathrm{~h})$ & $3.4(3.1-4.2)$ & $3.4(3.0-4.0)$ & 0.38 \\
Glucuronidation clearance $(\mathrm{ml} /$ min per kilogram) & $2.9(2.3-3.8)$ & $3.3(2.4-4.1)$ & 0.42 \\
Glucuronide/APAP AUC (ratio) & $2.8(2.1-3.7)$ & $2.7(2.1-3.9)$ & 0.66 \\
APAP sulfate $\mathrm{t}_{1 / 2}(\mathrm{~h})$ & $3.1(2.9-3.6)$ & $3.2(2.8-3.9)$ & 0.34 \\
Sulfation clearance (ml/min per kilogram) & $1.4(1.1-1.7)$ & $1.7(1.3-2.2)$ & 0.06 \\
Sulfate/APAP AUC (ratio) & $0.88(0.71-1.04)$ & $0.94(0.68-1.23)$ & 0.35 \\
Oxidation clearance $(\mathrm{ml} / \mathrm{min}$ per kilogram) & $0.90(0.65-1.15)$ & $0.57(0.49-0.77)$ & 0.0001 \\
APAP protein-adduct $(\mathrm{nmol} / \mathrm{ml})$ & $0.021(0.016-0.027)$ & $0.018(0.010-0.026)$ & 0.11 \\
\hline
\end{tabular}

${ }^{a} t$ Test on log-transformed data or Mann-Whitney rank sum test for plasma APAP protein-adduct concentrations 
TABLE 3

Comparisons of APAP pharmacokinetic parameters in study subjects by gender

Data presented as median (interquartile range).

\begin{tabular}{|c|c|c|c|}
\hline Parameter & $\begin{array}{c}\text { Men } \\
(N=52)\end{array}$ & $\begin{array}{c}\text { Women } \\
(N=43)\end{array}$ & $P$ value $^{a}$ \\
\hline APAP $t_{1 / 2}(h)$ & $2.7(2.4-3.1)$ & $2.4(2.2-2.6)$ & 0.0009 \\
\hline APAP plasma clearance $(\mathrm{ml} / \mathrm{min}$ per kilogram $)$ & $5.6(4.8-6.6)$ & $5.4(4.8-6.6)$ & 0.74 \\
\hline APAP renal clearance $(\mathrm{ml} / \mathrm{min}$ per kilogram $)$ & $0.16(0.13-0.21)$ & $0.19(0.15-0.24)$ & 0.067 \\
\hline APAP glucuronide $t_{1 / 2}(h)$ & $3.7(3.3-4.4)$ & $3.2(2.9-3.6)$ & 0.0002 \\
\hline Glucuronidation clearance ( $\mathrm{ml} / \mathrm{min}$ per kilogram) & $3.0(2.4-4.1)$ & $3.0(2.3-3.8)$ & 0.97 \\
\hline Glucuronide/APAP AUC (ratio) & $3.0(2.1-4.0)$ & $2.5(1.9-3.1)$ & 0.049 \\
\hline APAP sulfate $t_{1 / 2}(h)$ & $3.5(3.0-3.9)$ & $3.1(2.8-3.2)$ & 0.002 \\
\hline Sulfation clearance (ml/min per kilogram) & $1.4(1.2-1.8)$ & $1.6(1.1-1.9)$ & 0.65 \\
\hline Sulfate/APAP AUC (ratio) & $0.94(0.79-1.14)$ & $0.81(0.61-1.03)$ & 0.025 \\
\hline Oxidation clearance (ml/min per kilogram) & $0.76(0.56-0.97)$ & $0.75(0.58-1.13)$ & 0.52 \\
\hline APAP protein-adduct (nmol/ml) & $0.021(0.015-0.027)$ & $0.020(0.013-0.028)$ & 0.52 \\
\hline
\end{tabular}

${ }^{a} \mathrm{t}$ Test on log-transformed data or Mann-Whitney rank sum test for plasma APAP protein-adduct concentrations.

variability). None of the independent variables evaluated were associated with acetaminophen sulfation clearance or sulfate-to-acetaminophen AUC ratios.

\section{Discussion}

The major findings of this study are that race, gender, and some genetic polymorphisms contribute to individual variability in acetaminophen pharmacokinetics, metabolism, and plasma acetaminophen protein-adduct concentrations. The effect of race was relatively modest resulting in $37 \%$ lower acetaminophen oxidation in African-Americans, without discernible differences in acetaminophen glucuronidation, sulfation, or total plasma clearance. These results largely agree with a prior study that showed lower (by 44-53\%) 24-hour fractional urinary recovery of glutathione-derived acetaminophen conjugates in black Ghanaians (5.2\% of total excreted) and Kenyans (4.4\% of total excreted) versus Scottish whites (9.3\% of total excreted), and unchanged sulfate recovery (Critchley et al., 1986). However, they also reported slightly higher (by 7.4\%) acetaminophen glucuronide recovery for black Africans compared with white Europeans. Although we also observed a trend for higher median acetaminophen glucuronidation clearance values in African-Americans (3.3 $\mathrm{ml} / \mathrm{min}$ per kilogram) versus European-Americans $(2.9 \mathrm{ml} / \mathrm{min}$ per kilogram), this difference $(14.4 \%)$ did not reach statistical significance $(P=0.42)$. One possible reason for this discrepancy is that the African-American population in the United States is more genetically diverse than Ghanaian and Kenyan populations, which could increase individual variability in acetaminophen metabolism and somewhat limit the ability to detect a population difference. Other reasons could be methodological: We used a somewhat lower acetaminophen dose ( $1 \mathrm{~g}$ versus $1.5 \mathrm{~g}$ ), collected urine for 12 hours instead of 24 hours, and studied a somewhat smaller number of African-Americans (41) versus Ghanaians (67) and Kenyans (20).

We also observed shorter plasma half-life values for acetaminophen, acetaminophen glucuronide, and acetaminophen sulfate, and lower metabolite/acetaminophen AUC ratios in women versus men, without any difference in acetaminophen or metabolite clearance. These findings are consistent with gender-related differences in drug and metabolite distribution rather than any effect on drug clearance and/or metabolism. Lower weight-adjusted acetaminophen volume of distribution has been previously reported in women compared with men (Divoll et al., 1982) and is probably a reflection of the relatively poor distribution of acetaminophen (and metabolites) into fatty tissue, which tends to provide a higher proportion of body weight in women than in men (Abernethy et al., 1982).

The UGT2B15*2 polymorphism was identified as a determinant of acetaminophen clearance and glucuronidation partial clearance. This finding is consistent with prior work that showed an association of the UGT2B15*2 allele with lower acetaminophen glucuronide-to-acetaminophen concentration ratios in urine (Navarro et al., 2011) and blood (Mehboob et al., 2016). Our work extends those findings to indicate an effect on total acetaminophen oral clearance, which reflects the important contribution of glucuronidationto-acetaminophen clearance ( $55 \%$ in this study). UGT2B15*2 was also associated with increased plasma concentrations of acetaminophen protein-adduct. Presumably this is because

TABLE 4

Comparison of minor allele frequencies in study subjects by race

\begin{tabular}{|c|c|c|c|}
\hline Enzyme Gene Variant & European-Americans $(N=53)$ & African-Americans $(N=41)$ & $P$ value $^{a}$ \\
\hline UGT1A rs8330 C/G & 0.21 & 0.51 & $<0.001$ \\
\hline UGT1A1 (TA)N=5or6/7or8 & 0.37 & 0.40 & 0.47 \\
\hline UGT1A6*2 rs6759892; rs2070959; rs1105879 & 0.42 & 0.30 & 0.02 \\
\hline UGT1A9 rs6714486 T/A & 0.05 & 0.14 & 0.007 \\
\hline UGT2B15*2 rs1902023 T/G & 0.50 & 0.44 & 0.21 \\
\hline SULT1A1*2 rs9282861 G/A & 0.36 & 0.28 & 0.07 \\
\hline CYP2E $1 * 1 \mathrm{D} 6->8$ repeats & 0.04 & 0.27 & $<0.001$ \\
\hline CYP2E1*4 rs6413419 G/A & 0.01 & 0.16 & $<0.001$ \\
\hline CYP3A5*3 rs776746 A/G & 0.94 & 0.38 & $<0.001$ \\
\hline
\end{tabular}

\footnotetext{
${ }^{a} \chi^{2}$ test.
} 


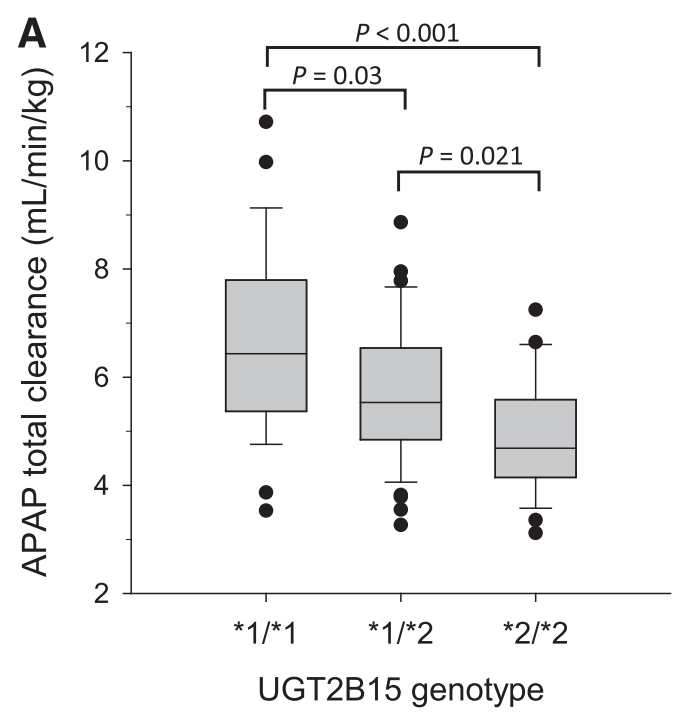

B

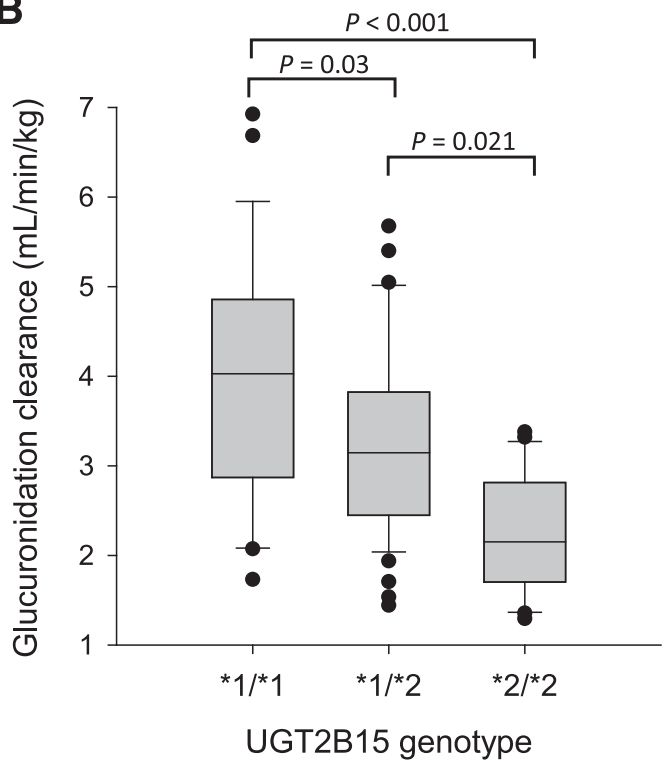

Fig. 4. Association of UGT2B15 genotype with acetaminophen (APAP) total plasma clearance (A) and partial urinary clearance by glucuronidation (B). Shown are box and whiskers plots of data grouped by UGT2B15 genotype, including genotypes $* 1 / * 1$ (27 subjects), $* 1 / * 2$ (45 subjects with total clearance data; 43 subjects with glucuronidation clearance data), and $* 2 / * 2$ (22 subjects). Also shown are the $P$ values that were significant $(<0.05)$ for comparisons between genotype groups by ANOVA with Holm-Sidak multiple comparisons testing on log-transformed data.

UGT2B15*2 causes decreased acetaminophen glucuronidation leading to increased availability of acetaminophen for oxidative metabolism to NAPQI, which then binds to proteins that can subsequently be detected in the plasma. In support of this, plasma acetaminophen protein-adduct concentrations were most strongly and negatively correlated with acetaminophen glucuronidation.

SULT1A1*2 was associated with decreased plasma acetaminophen sulfate to acetaminophen AUC ratios. This association, although relatively weak, remained significant even after possible race and gender effects were accounted for in the multivariate analysis. Although we did see a trend toward lower sulfation clearance in SULT1A1 *2/*2 individuals, this did not reach the statistical significance threshold in the univariate or multivariate analyses. The SULT1A1*2 variant

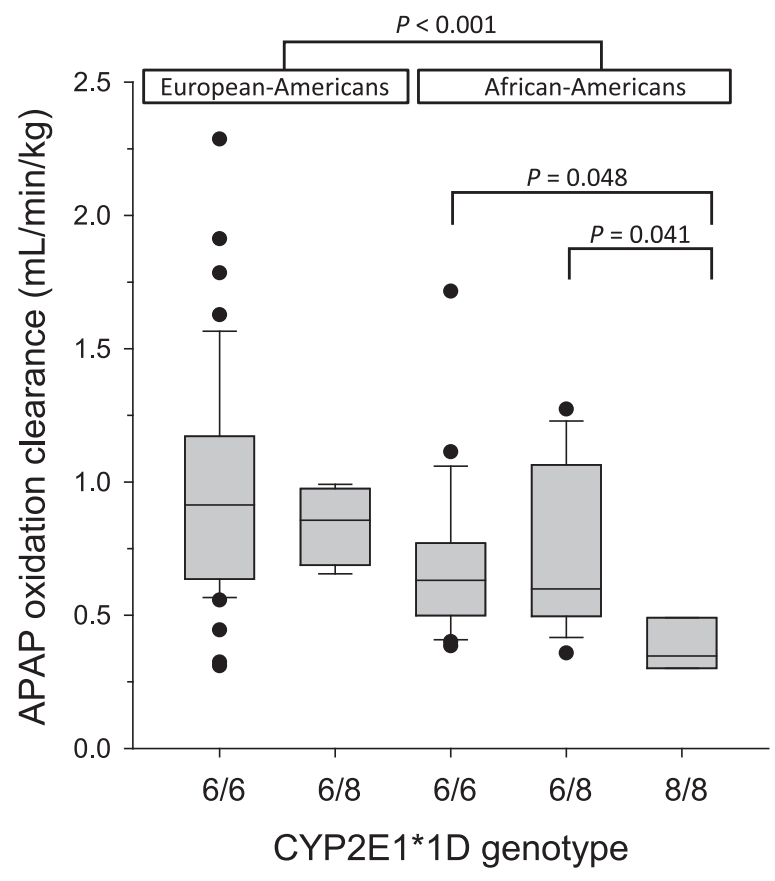

Fig. 5. Association of race (European-American or European-American) and CYP2E $1 * 1 \mathrm{D}$ genotype with partial urinary clearance of acetaminophen (APAP) by oxidation. Shown are box and whiskers plots of data grouped by CYP2E $1 * 1 \mathrm{D}$ genotype and race, including genotypes $* 1 \mathrm{C} / * 1 \mathrm{C}$ (49 European-Americans and 22 African-Americans), ${ }^{*} 1 \mathrm{C} / * 1 \mathrm{D}$ (4 EuropeanAmericans and 14 African-Americans), and *1D/*1D (3 African-Americans). No European-Americans had the $* 1 \mathrm{D} / * 1 \mathrm{D}$ genotype. Also shown are the $P$ values that were significant $(<0.05)$ for the comparison between EuropeanAmerican and African-American subjects by $t$ test on log-transformed data, and for comparisons between genotype groups within African-American subjects by ANOVA with Holm-Sidak multiple comparisons testing on logtransformed data.

has rarely been studied in the context of drug pharmacokinetics (Daniels and Kadlubar, 2014). Several studies have examined the association of SULT1A1*2 with the pharmacokinetics of tamoxifen and major oxidative metabolites (Jin et al., 2005; Gjerde et al., 2008). Although all of these failed to show a significant influence of this gene variant, none of the studies measured the sulfation metabolites directly. A more recent study evaluated the association of four different SULT1A1 gene variants with plasma pharmacokinetics of ABT-751, an experimental cancer treatment (Innocenti et al., 2013). Although they found no association of SULT1A1*2 with ABT-751 pharmacokinetics, they did find a significant association of a SULT1A1 gene copy number variant (CNV) with increased ABT-751 clearance and ABT-751 sulfate-toABT-751 AUC ratios. Consequently, future studies are needed to evaluate associations of acetaminophen sulfation with other SULT1A1 variants, particularly the SULT1A1 CNV.

Analysis of cytochrome P450 genotype associations with acetaminophen oxidation partial clearance was initially confounded by race effects since all of the cytochrome P450 genotypes examined differed markedly in frequencies between in African-Americans and European-Americans. However, after controlling for race effects, either by stratification by race or by multivariate analysis, the only variant that showed a significant association with reduced oxidation clearance was CYP2E1*1D. Given the much 


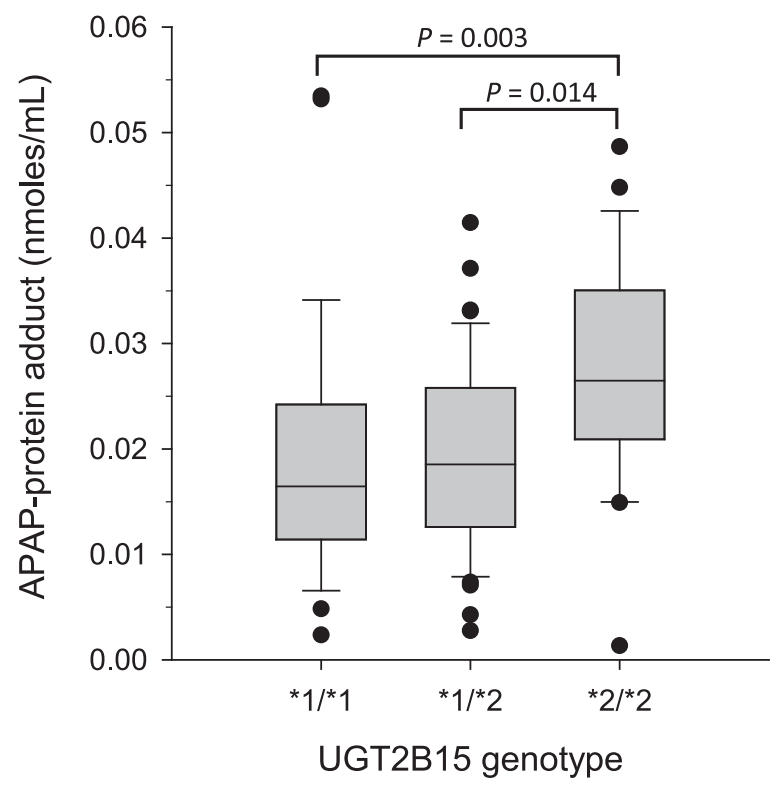

Fig. 6. Association of UGT2B15 genotype with APAP protein-adduct concentrations. Shown are box and whiskers plots of data grouped by UGT2B15 genotype, including genotypes $* 1 / * 1$ ( 27 subjects), $* 1 / * 2$ (44 subjects), and $* 2 / * 2$ (21 subjects). Also shown are the $P$ values that were significant $(>0.05)$ for comparisons between genotype groups by Kruskal-Wallis ANOVA with Dunn's multiple comparisons testing on rank-transformed data.

higher frequency of CYP2E1*1D in black African-derived populations, it is probable that this allele accounts for a proportion of the race-related variability in acetaminophen oxidation. However, since race remained a significant covariate in the multivariate analysis, it is probable that other factors influencing acetaminophen oxidation in Africanderived populations, including additional genetic polymorphisms, have yet to be discovered. We did not observe a significant association between CYP2E1*1D genotype and acetaminophen protein-adduct concentrations. This may be because we assayed acetaminophen protein-adduct concentrations at a single time point corresponding to the expected $\mathrm{T}_{\max }(8$ hours), rather than over the entire sampling time.

The genetic variants associated with acetaminophen metabolism in the current study (UGT2B15*2, SULT1A1*2, and
CYP2E1*1D; but not UGT1A rs8330 or CYP3A5*3) differ from those associated with acetaminophen-induced liver failure in our prior studies (UGT1A rs8330 and CYP3A5*3; but not UGT2B15*2, SULT1A1*2, or CYP2E1*1D) (Court et al., 2013; Court et al., 2014). The most probable reason for this difference is the higher acetaminophen dose (usually over $10 \mathrm{~g}$ ) consumed in acetaminophen-induced liver failure patients leading to much higher plasma concentrations compared with the therapeutic dose $(1 \mathrm{~g})$ used here. Consequently, alternate glucuronidation, sulfation, and oxidation enzymes may become quantitatively more important for acetaminophen metabolism at these higher concentrations. Interestingly, although UGT2B15 appears to be the predominant acetaminophen glucuronidation enzyme at therapeutic concentrations $(0.1 \mathrm{mM}$ or less), recombinant enzyme studies indicate that there is substantial substrate inhibition of UGT2B15 at higher concentrations $(10 \mathrm{mM}$ or higher) (Mutlib et al., 2006). Consequently, other hepatic acetaminophen glucuronidation enzymes, including UGT1A1, UGT1A6, and UGT1A9, which do not demonstrate substrate inhibition, appear to predominate at these higher substrate concentrations (Mutlib et al., 2006). These enzymes are all affected by the rs 8330 variant located in the 3 '-UTR region of the UGT1A gene.

In summary, our results indicate that acetaminophen total clearance and partial metabolic clearance by glucuronidation and sulfation are similar in healthy adult African-Americans compared with European-Americans. However, AfricanAmericans, like black Africans from Kenya and Ghana, metabolize acetaminophen by oxidation more slowly than European-derived populations. This difference may be partially explained by the CYP2E $1 * 1 \mathrm{D}$ polymorphism, which is more prevalent in black African-derived populations. UGT2B15*2 was also identified as a determinant of lower acetaminophen clearance by glucuronidation and higher circulating acetaminophen protein-adduct concentrations in both European-American and African-American populations.

\section{Authorship Contributions}

Participated in research design: Court, Greenblatt.

Conducted experiments: Court, Zhu, Masse, Duan, James.

Performed data analysis: Court, Masse, Harmatz.

Wrote or contributed to the writing of the manuscript: Court, James, Greenblatt.

TABLE 5

Results of multivariate analysis by multiple linear regression evaluating the contributions of subject race, gender, and enzyme genotypes to variability in APAP pharmacokinetic parameters

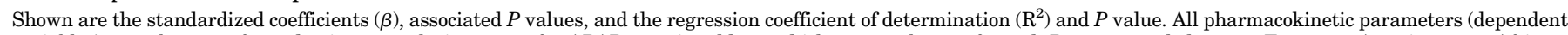

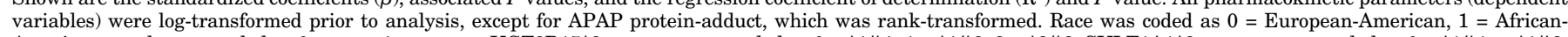

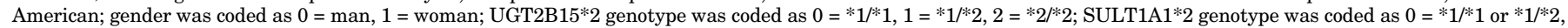
$1=* 2 / * 2$; CYP2E $1 * 1 \mathrm{D}$ genotype was coded as $0=* 1 \mathrm{C} / * 1 \mathrm{C}$ or $* 1 \mathrm{C} / * 1 \mathrm{D}, 1=* 1 \mathrm{D} / * 1 \mathrm{D}$.

\begin{tabular}{|c|c|c|c|c|c|c|c|c|c|c|c|c|}
\hline \multirow{2}{*}{ Dependent Variable } & \multicolumn{2}{|c|}{ Race } & \multicolumn{2}{|c|}{ Gender } & \multicolumn{2}{|c|}{ UGT2B15*2 } & \multicolumn{2}{|c|}{ SULT1A1*2 } & \multicolumn{2}{|c|}{ CYP2E1*1D } & \multirow[b]{2}{*}{$\mathrm{R}^{2}$} & \multirow[b]{2}{*}{$P$ value } \\
\hline & $\beta$ & $P$ value & $\beta$ & $P$ value & $\beta$ & $P$ value & $\beta$ & $P$ value & $\beta$ & $P$ value & & \\
\hline APAP clearance & 0.03 & 0.74 & -0.01 & 0.89 & -0.40 & $<0.001$ & -0.03 & 0.81 & 0.03 & 0.78 & 0.17 & 0.006 \\
\hline Glucuronidation clearance & 0.04 & 0.72 & -0.08 & 0.45 & -0.53 & $<0.001$ & 0.02 & 0.86 & 0.09 & 0.33 & 0.29 & $<0.001$ \\
\hline Glucuronide/APAP AUC & 0.04 & 0.67 & -0.26 & 0.008 & -0.51 & $<0.001$ & -0.01 & 0.89 & 0.08 & 0.40 & 0.31 & $<0.001$ \\
\hline Sulfation clearance & 0.23 & 0.04 & 0.03 & 0.80 & -0.06 & 0.59 & -0.12 & 0.30 & -0.13 & 0.23 & 0.08 & 0.20 \\
\hline Sulfate/APAP AUC & 0.17 & 0.11 & -0.20 & 0.07 & -0.01 & 0.89 & -0.21 & 0.06 & -0.05 & 0.65 & 0.12 & 0.05 \\
\hline Oxidation clearance & -0.36 & $<0.001$ & 0.12 & 0.25 & 0.09 & 0.34 & 0.06 & 0.55 & -0.23 & 0.02 & 0.23 & $<0.001$ \\
\hline APAP protein-adduct & -0.08 & 0.44 & 0.04 & 0.72 & 0.37 & $<0.001$ & -0.18 & 0.09 & -0.17 & 0.10 & 0.19 & 0.003 \\
\hline
\end{tabular}




\section{References}

Abernethy DR, Divoll M, Greenblatt DJ, and Ameer B (1982) Obesity, sex, and acetaminophen disposition. Clin Pharmacol Ther 31:783-790.

Ameer B and Greenblatt DJ (1977) Acetaminophen. Ann Intern Med 87:202-209.

Court MH, Duan SX, von Moltke LL, Greenblatt DJ, Patten CJ, Miners JO, and Mackenzie PI (2001) Interindividual variability in acetaminophen glucuronidation by human liver microsomes: identification of relevant acetaminophen UDP-glucuronosyltransferase isoforms. J Pharmacol Exp Ther 299:998-1006.

Court MH, Freytsis M, Wang X, Peter I, Guillemette C, Hazarika S, Duan SX, Greenblatt DJ, and Lee WM; Acute Liver Failure Study Group (2013) The UDP-glucuronosyltransferase (UGT) 1A polymorphism c.2042C $>$ G (rs8330) is associated with increased human liver acetaminophen glucuronidation, increased UGT1A exon 5a/5b splice variant mRNA ratio, and decreased risk of unintentional acetaminophen-induced acute liver failure. J Pharmacol Exp Ther 345:297-307.

Court MH, Peter I, Hazarika S, Vasiadi M, Greenblatt DJ, and Lee WM; Acute Liver Failure Study Group (2014) Candidate gene polymorphisms in patients with acetaminophen-induced acute liver failure. Drug Metab Dispos 42:28-32.

Critchley JA, Critchley LA, Anderson PJ, and Tomlinson B (2005) Differences in the single-oral-dose pharmacokinetics and urinary excretion of paracetamol and its conjugates between Hong Kong Chinese and Caucasian subjects. J Clin Pharm Ther 30:179-184.

Critchley JA, Nimmo GR, Gregson CA, Woolhouse NM, and Prescott LF (1986) Intersubject and ethnic differences in paracetamol metabolism. Br J Clin Pharmacol 22: 649-657.

Daniels J and Kadlubar S (2014) Pharmacogenetics of SULT1A1. Pharmacogenomics 15:1823-1838.

Davern TJ, 2nd, James LP, Hinson JA, Polson J, Larson AM, Fontana RJ, Lalani E Munoz S, Shakil AO, and Lee WM Acute Liver Failure Study Group (2006) Measurement of serum acetaminophen-protein adducts in patients with acute liver failure. Gastroenterology 130:687-694.

Divoll M, Abernethy DR, Ameer B, and Greenblatt DJ (1982) Acetaminophen kinetics in the elderly. Clin Pharmacol Ther 31:151-156.

Girard H, Thibaudeau J, Court MH, Fortier LC, Villeneuve L, Caron P, Hao Q, von Moltke LL, Greenblatt DJ, and Guillemette C (2005) UGT1A1 polymorphisms are important determinants of dietary carcinogen detoxification in the liver. Hepatology 42:448-457.

Gjerde J, Hauglid M, Breilid H, Lundgren S, Varhaug JE, Kisanga ER, Mellgren G, Steen VM, and Lien EA (2008) Effects of CYP2D6 and SULT1A1 genotypes including SULT1A1 gene copy number on tamoxifen metabolism. Ann Oncol 19: $56-61$.

Heard KJ, Green JL, James LP, Judge BS, Zolot L, Rhyee S, and Dart RC (2011) Acetaminophen-cysteine adducts during therapeutic dosing and following overdose. BMC Gastroenterol 11:20.

Innocenti F, Ramírez J, Obel J, Xiong J, Mirkov S, Chiu YL, Katz DA, Carr RA Zhang W, Das S, et al. (2013) Preclinical discovery of candidate genes to guide pharmacogenetics during phase I development: the example of the novel anticancer agent ABT-751. Pharmacogenet Genomics 23:374-381.

James LP, Alonso EM, Hynan LS, Hinson JA, Davern TJ, Lee WM, and Squires RH; Pediatric Acute Liver Failure Study Group (2006) Detection of acetaminophen protein adducts in children with acute liver failure of indeterminate cause. Pediatrics 118: 676 -e681.

James LP, Chiew A, Abdel-Rahman SM, Letzig L, Graudins A, Day P, and Roberts D (2013) Acetaminophen protein adduct formation following low-dose acetaminophen exposure: comparison of immediate-release vs extended-release formulations. Eur $J$ Clin Pharmacol 69:851-857.

Jin Y, Desta Z, Stearns V, Ward B, Ho H, Lee KH, Skaar T, Storniolo AM, Li L, Araba A, et al. (2005) CYP2D6 genotype, antidepressant use, and tamoxifen metabolism during adjuvant breast cancer treatment. J Natl Cancer Inst 97:30-39.

Kaufman DW, Kelly JP, Rosenberg L, Anderson TE, and Mitchell AA (2002) Recent patterns of medication use in the ambulatory adult population of the United States: the Slone survey. JAMA 287:337-344.

Khandelwal N, James LP, Sanders C, Larson AM, and Lee WM; Acute Liver Failure Study Group (2011) Unrecognized acetaminophen toxicity as a cause of indeterminate acute liver failure. Hepatology 53:567-576.

Larson AM, Polson J, Fontana RJ, Davern TJ, Lalani E, Hynan LS, Reisch JS, Schiødt FV, Ostapowicz G, Shakil AO, et al.; Acute Liver Failure Study Group (2005) Acetaminophen-induced acute liver failure: results of a United States multicenter, prospective study. Hepatology 42:1364-1372.

Mehboob H, Iqbal T, Jamil A, and Khaliq T (2016) Genetic polymorphism of UDPglucuronosyltransferase (UGT2B15) and glucuronidation of paracetamol in healthy population. Pak J Pharm Sci 29(3, Suppl):1037-1041.

Mitchell JR, Thorgeirsson SS, Potter WZ, Jollow DJ, and Keiser H (1974) Acetaminophen-induced hepatic injury: protective role of glutathione in man and rationale for therapy. Clin Pharmacol Ther 16:676-684.

Mutlib AE, Goosen TC, Bauman JN, Williams JA, Kulkarni S, and Kostrubsky S (2006) Kinetics of acetaminophen glucuronidation by UDP-glucuronosyltransferases 1A1, 1A6, 1A9 and 2B15. Potential implications in acetaminophen-induced hepatotoxicity. Chem Res Toxicol 19:701-709.

Navarro SL, Chen Y, Li L, Li SS, Chang JL, Schwarz Y, King IB, Potter JD, Bigler J, and Lampe JW (2011) UGT1A6 and UGT2B15 polymorphisms and acetaminophen conjugation in response to a randomized, controlled diet of select fruits and vegetables. Drug Metab Dispos 39:1650-1657.

Rauchschwalbe SK, Zühlsdorf MT, Wensing G, and Kuhlmann J (2004) Glucuronidation of acetaminophen is independent of UGT1A1 promotor genotype. Int $J$ Clin Pharmacol Ther 42:73-77.

Tankanitlert J, Morales NP, Howard TA, Fucharoen P, Ware RE, Fucharoen S, and Chantharaksri U (2007) Effects of combined UDP-glucuronosyltransferase (UGT) $1 \mathrm{~A} 1 * 28$ and $1 \mathrm{~A} 6 * 2$ on paracetamol pharmacokinetics in beta-thalassemia/ HbE. Pharmacology 79:97-103.

Zhao Y, Harmatz JS, Epstein CR, Nakagawa Y, Kurosaki C, Nakamura T, Kadota T, Giesing D, Court MH, and Greenblatt DJ (2015) Favipiravir inhibits acetaminophen sulfate formation but minimally affects systemic pharmacokinetics of acetaminophen. Br J Clin Pharmacol 80:1076-1085.

Address correspondence to: Dr. Michael H. Court, Pharmacogenomics Laboratory, Department of Veterinary Clinical Sciences, Washington State University College of Veterinary Medicine, 100 Grimes Way, Pullman, WA 99163. E-mail: michael.court@vetmed.wsu.edu. 